\title{
Mortality rates and life expectancy improvements among Malaysian elderlies
}

\author{
Nur Shatikah Mohamad Ibrahim, Syazreen Niza Shair, Aida Yuzi Yusof \\ Centre for Actuarial Studies, Faculty of Computer and Mathematical Sciences, \\ Universiti Teknologi Mara Shah Alam, Malaysia
}

\begin{tabular}{|c|c|}
\hline Article Info & ABSTRACT \\
\hline $\begin{array}{l}\text { Article history: } \\
\text { Received Dec 14, } 2019 \\
\text { Revised Feb 3, 2020 } \\
\text { Accepted Feb 20, } 2020\end{array}$ & $\begin{array}{l}\text { This paper presents a study on mortality rates and life expectancy } \\
\text { improvements among elderly people in Malaysia. The central age-specific } \\
\text { mortality rates will be analyzed according to genders. The expectation of } \\
\text { future lifetime of these old age people will be estimated using the actuarial life } \\
\text { table approach. Two different types of life table will be developed, including } \\
\text { life table for males and females, to compare the results of mortality rates and }\end{array}$ \\
\hline $\begin{array}{l}\text { Keywords: } \\
\text { Elderly's } \\
\text { Life expectancy } \\
\text { Life table } \\
\text { Longevity risk } \\
\text { Mortality rates }\end{array}$ & $\begin{array}{l}\text { life expectancies between genders. Results show that, mortality rates of } \\
\text { Malaysian elderly, for both males and females are increasing almost in linear } \\
\text { pattern by age, and this trend is consistent from } 1950 \text { to } 2015 \text {. Comparison } \\
\text { between genders shows that mortality of elderly females is generally lower } \\
\text { than males at almost all ages. Nonetheless, mortality rates of Malaysian elderly } \\
\text { males are declining faster than Malaysian elderly females. Life expentancies } \\
\text { of females are higher than males for age groups } 60 \text { to } 70 \text {, and lower than males } \\
\text { for age } 75 \text { and above. Results also indicate that Malaysian elderly popultion is } \\
\text { aging faster from previous generation in which elderly males age } 85+\text { in } \\
2010-2015 \text { can live longer by } 123 \% \text { than thise in } 1950-1955 \text {. }\end{array}$ \\
\hline
\end{tabular}

Copyright $(92020$ Institute of Advanced Engineering and Science. All rights reserved.

\section{Corresponding Author:}

Nur Shatikah Binti Mohamad Ibrahim,

Faculty of Computer and Mathematical Sciences,

Universiti Teknologi Mara Shah Alam,

Jalan Ilmu 1/1, 40450 Shah Alam, Selangor, Malaysia.

Email: ijeecs.iaes@gmail.com

\section{INTRODUCTION}

Nowadays, population of older people has been growing rapidly all over the world and this phenomenon also known as population aging. Population aging happens when life expectancy of the whole population increases whereas the mortality rates decreases over the years with confluence of low fertility rate. The life expectancy has improved due to some factors such as socio-economic status, medical improvement, nutrition \& diet, lifestyle and living environment. These changes seem a good improvement achieved by the country, however it actually affects other parties such as policy makers and insurance companies.

Population aging has occurred in many countries, and has been observed in [1-4]. According to [5], Malaysia will be an ageing nation in year 2030, which is when $14 \%$ of the population will be those who are aged 60 years old and over while in [6], it reported that Malaysia prepares to be an aging country when $7 \%$ of the people reach 65 years and older by 2030 . I has been reported that by year 2050, the worldwide population age 60 years old and above will increase by more than three times [7]. Some developed countries already reached an aging population status. For example, in Australia, the percentage of people age 65 years and above for the year 2018 is $16.44 \%$ representing $24,898,152$ people.

In relation to this ageing issue, the Malaysian Government has raised the retirement age for both public and private sector employees from 55 years old (private sector) and 58 years old (public sector) to 60 years old 
in 2014 [5]. These changes reflect longevity risk: the risk that people live longer than expected as a result from the uncertainties in mortality patterns [8]. The Malaysian population age-structure is experiencing major modifications that is the percentage of the working-age population will reduce while the percentage of old age people will develop considerably after some time, leading to population ageing [9-11]. This provides challenge to the nation as it will cause problems especially through government spending on pensions, healthcare, and social programs.

The trends of mortality rates by specific age group and gender in Malaysia has been observed by [12] and [13], and yet results showed that more services are needed to improve the elderly needs and wellbeing since the number of elderlies are increasing recently. Although there are numerous researchers studied on Malaysians population mortality rates, only few study had focus on elderly groups. The study conducted in [14] proposed a new hazard function that implies the conditional specific on frailty. Research study in [15] have reviewed the trends and patterns of old age mortality and cause-of-death for Eastern and South-Eastern Asian countries in general by examining the data on old age mortality in terms of life expectancy at age 65 , age-specific death rates and the data on cause-of-death accordingly. However, as far as we concern, no previous study have really estimate the speed of aging among Malaysian elderlies. This kind of indicator is important to help government to plan and take proper action.

The life table approach will be implemented for evaluating and comparing mortality current conditions in populations [16]. Actuarial life table is commonly described as a valuable analytical tool for demographers, epidemiologists, actuaries and other researchers. According to [17], life table is developed to measure mortality, survivorship and life expectancy for people of every age and sex. It fits the mortality experience of a population at various ages into a single descriptive statistical model. In [18] stated that the life table is a key summary tool for evaluating and comparing mortality conditions in populations. In addition, life table analysis encourages comparison of mortality experience between different population [19]. Furthermore, life tables provide a relationship between mortality and life expectancy [20]. Thus, this research developes life table for Malaysian elderlies and to analyse its trends over the years.

This paper presents the mortality rates and life expectancy improvements among Malaysian elderlies to analyze central death rates of Malaysia elderly and to estimate the life expectancies of Malaysian elderly using actuarial life table approach. Furthermore, to know how fast the Malaysian population aging, life expectancy improvement will be estimated.

\section{RESEARCH METHODS} as in (1):

In this study, we estimate the age-specific central death rates of Malaysia elderly using formula

$$
M x, t=\frac{D x, t}{P x, t}
$$

where:

$M x, t$ is the central death rate of elderlies age $x$ in year $t$

$D x, t$ is the number of death of elderlies age $x$ in year $t$ and

$P x, t$ is the number of elderly population age $x$ in mid year as of 1 July in year $t$

It is noteworthy that data for the number of death and population of Malaysian elderlies $D x, t$ were obtained from the [13] and in five-year age and time intervals. Once the central death rates are estimated, the Malaysian elderlies' life expectancies are estimated using the standard actuarial life table approach. Next, in order to estimate the life expectancy of old-age, we follow and apply the formulas and notations used in [17] to develop Malaysian life tables and described as in the Table 1.

Table 1 represents the life table approach that include several components. $n M x$ is the central death rate, $n q x$ is the probability of person age $x$ dies before age $x+n$ and $n p x$ is the compliment of $n q x$ which is equal to $1-n q x$. The $l_{x}$ is referred to the number of people who survive to age $\mathrm{x}$ and this is based on a radix. $n d x$ is the number of people who die between age $x$ and $x+n$ while $n L x$ express the number of person years lived between age $x$ and $x+n . S(x, n)$ will indicate the survival function whereas $T x$ is referred as the total number of person years lived after age $x$. Lastly, $e_{x}$ is the life expectancy at for a person age $x$. The developed life table will compare the relationship between mortality rates and life expectancies between genders among elderlies in Malaysia. 
Table 1. Life table notations and formulas

\begin{tabular}{cclc}
\hline Column & Notation & \multicolumn{1}{c}{ Definition } & Formulae \\
\hline 1 & $\mathrm{x}$ & Age & - \\
3 & $\mathrm{n}$ & Age interval & - \\
3 & $n M x$ & Central death rate & $n M x=\frac{n D x}{n P x}$ \\
4 & $n q x$ & Probability of dying & $n q x=\frac{n(n M x)}{(1+n(1-a)(n M x))}$ \\
5 & $n p x$ & Probability of surviving & $n p x=1-n q x$ \\
6 & $l_{x}$ & Number of survivors & $l_{x}=\frac{l(x+n)}{n P x}$ \\
7 & $n d x$ & Number of deaths & $n d x=l x-l(x+n)$ \\
8 & $n L x$ & Number of person-years lived & $n L x=\frac{n D x}{n M x}$ \\
9 & $S(x, n)$ & Survival ratio & $S(x, n)=\frac{n L(x+n)}{n L x}$ \\
10 & $T x$ & Persons-year lived & $T x=T(x+n)+n L x$ \\
11 & $e_{x}$ & Expectation of life & $e_{x}=\frac{T x}{n L x}$ \\
\hline
\end{tabular}

\section{RESULTS AND DISCUSSION}

Figure 1 are plotted using the results obtained from the (1). The full black lines represent Malaysian elderlies' log central death rates in year 1950 whereas the dashed lines represent year 2015. Firstly, we compare mortality of elderlies by different age groups. Generally, mortality rates of Malaysian elderly males and females are increasing almost in linear pattern by age, and this trend is consistent from 1950 to 2015. The increase in elderlies' mortality by age due to the tendency to have more health problems at higher ages. According to [21], age also could be part of the possible factors that affect muscle activity. More worrisome, the growth of Malaysia elderly's population recorded higher level of disability and frailty in the society [22].

Secondly, the comparison of mortality rates between genders shows that the mortality rates among Malaysian elderly females are generally lower than males at almost all ages. This shows that, in terms of mortality, elderly women are healthier and live longer than men, which is consistent with few studies like [23-25]. For example, for age 60, the log mortality rate for females in 1950 was lower than males which are -1.67086 compared to -1.5453785 . Consistently, for age 85 , female's log death rate is -0.71627 compared to -0.60983 for males. In line with other countries' mortality trends by gender, it is reported that in United States (US), mortality rates of females are consistently lower compared to males [26]. However, it is noteworthy that in 2015 , for age 80 years old and older the mortality rate of females is higher than males.

Finally, it is interesting to know how mortality rates of Malaysian elderlies decreased by year from 1950 to 2015 for both genders. This trend is usually called as "mortality improvement". From the Figure 1, a decline in mortality from 1950 to 2015 shows by gaps between full lines and dashed lines. For males, wider gaps can be seen for age groups 70 years and older compared to those below 70 years old. Whereas for females, the gap is narrower as age increases, indicating the mortality rates does not improves much for older groups. This shows that the mortality rates of Malaysian elderly males are improving faster than Malaysian elderly females. This finding contradicts the trend in East Asian region where females had faster mortality decline than males' [15]. An enormous improvement in public health and Medicare led to an overall decrease in death rates. Malaysia has shown a positive trend on their people's health status as a result of the government's emphasizing on the health care technology development and improvement.

Once the central death rates of Malaysian elderlies were estimated, we develop the life tables for each gender by calculating each component of life tables. See Tables 2 and 3 for complete life tables of Malaysian Elderlies. Tables 2 and 3 show life expentancies of females are higher than males for age groups 60 to 70 , then lower than males for age 75 and above. The life expectancies of Malaysian elderly males and females age 60 in 2015 are 21.32 and 22.73 years, indicating the 60 -year old women can live longer than men. In contrast, for the oldest old age group which are those who are aged 85 and above, elderly males are expected to live longer than females--- 9.05 years for males and 7.62 years for females. Next, we estimate how rapid the life expectancy increases by years and results are presented in Table 4 .

Table 4 shows that the life expectancy for Malaysian elderly is generally continue increasing from year 1950-1955 to 2010-2015 for all elderlies age 60 years old above. For Malaysian males who reach age of 60 years old in year 2010-2015, they were expected to live for another 21.32 years, compared to the same age population in 1950-1955 the life expectancy was only 14.56. This means that newer generation can live longer by $46 \%$ than previous generation. Similarly, Malaysian elderly female's age 60 years in 2010-2015 were expected to live for another 22.73 years increased by 5.75 years (34\%) as compared to those in 150-1955. Elderly males age $85+$ shows the highest percentage of life expectancy improvement in which newer generation 
can live longer more than double compared to older generation. Males age $85+$ in $2010-2015$ can live up to 9.07 years, which is $123 \%$ longer than those in 1950-1955. Although these findings seem good news to some people, it is often overlooked. For instances, infrastructure, work opportunities, family support and health care facilities are some of the crucial areas that require change to help the expected need of this old age throughout their survival years.

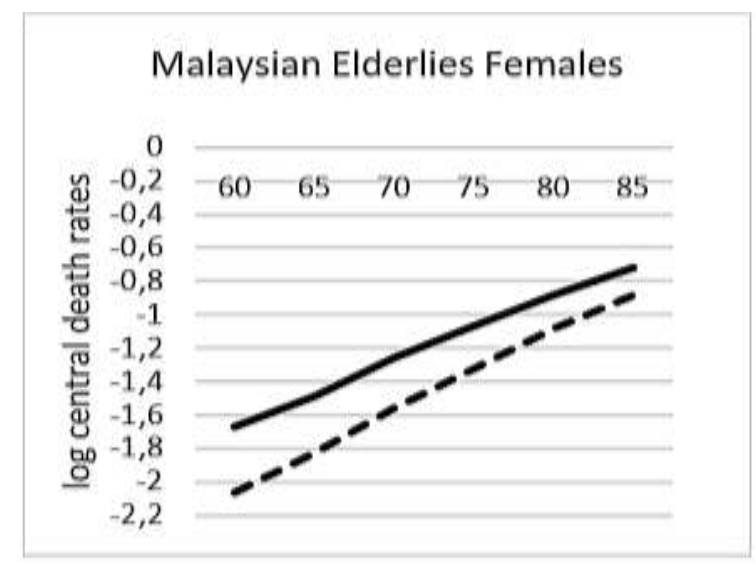

(a)

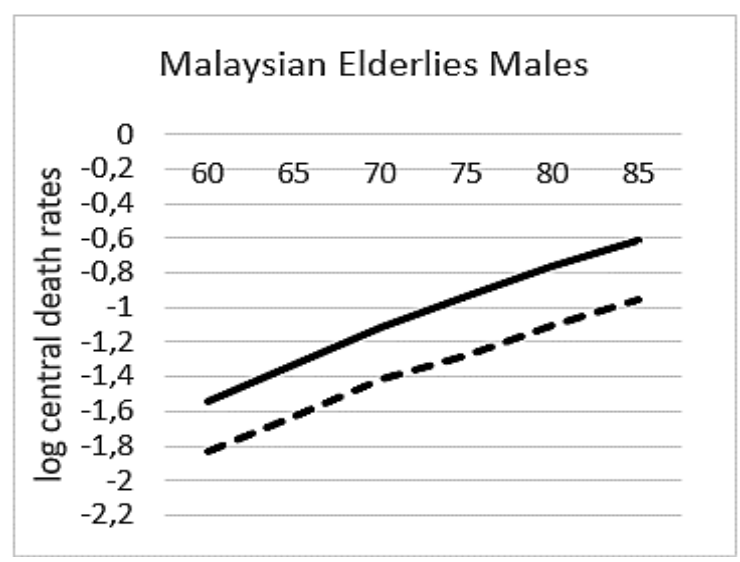

(b)

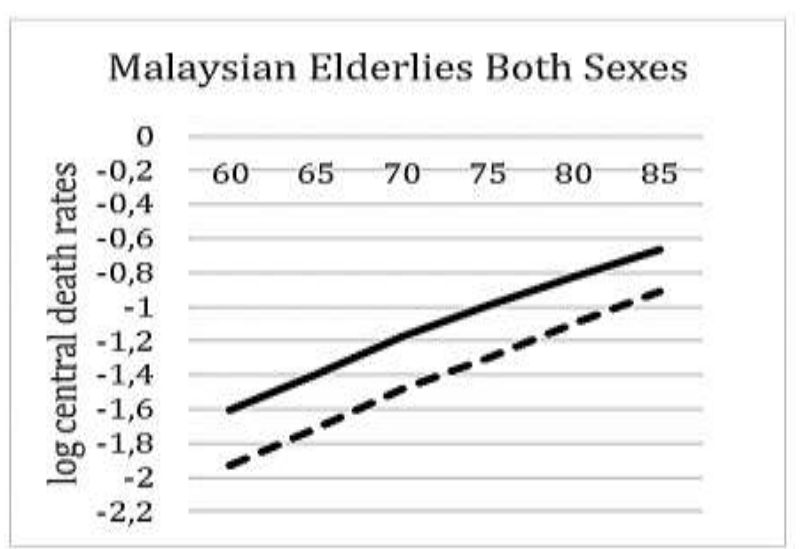

(c)

Figure 1. The estimated log central death rates $M_{x, t}$ of Malaysian elderlies males, (a) females (b) and both genders (c) from year 1950 (full line) to 2015 (dashed line)

Table 2. Malaysian elderly males mortality table in year 2010-2015

\begin{tabular}{ccccccccccccc}
\hline$x$ & $n$ & ${ }_{n} P_{x}$ & ${ }_{n} D_{x}$ & ${ }_{n} M_{x}$ & $a$ & ${ }_{n} q_{x}$ & ${ }_{n} p_{x}$ & $l_{x}$ & ${ }_{n} d_{x}$ & ${ }_{n} L_{x}$ & $T_{x}$ \\
\hline 60 & 5 & 2782545 & 41203 & 0.01481 & 0.5 & 0.07140 & 0.9286 & 85,355 & 6,094 & 411539 & $1,819,722$ & 21.32 \\
65 & 5 & 1915831 & 45587 & 0.02379 & 0.5 & 0.11229 & 0.8877 & 79,261 & 8,901 & 374053 & $1,408,183$ & 17.77 \\
70 & 5 & 1262199 & 48232 & 0.03821 & 0.5 & 0.17440 & 0.8256 & 70,360 & 12,271 & 321124 & $1,034,131$ & 14.70 \\
75 & 5 & 838859 & 44804 & 0.05341 & 0.5 & 0.23560 & 0.7644 & 58,089 & 13,686 & 256232 & 713,007 & 12.27 \\
80 & 5 & 418709 & 32707 & 0.07811 & 0.5 & 0.32676 & 0.6732 & 44,404 & 14,509 & 185745 & 456,774 & 10.29 \\
85 & 5 & 162276 & 17899 & 0.11030 & & 1.00000 & 0.0000 & 29,894 & 29,894 & 271029 & 271,029 & 9.07 \\
\hline
\end{tabular}

Table 3. Malaysian elderly females mortality table in year 2010-2015

\begin{tabular}{ccccccccccccc}
\hline$x$ & $n$ & ${ }_{n} P_{x}$ & ${ }_{n} D_{x}$ & ${ }_{n} M_{x}$ & $a$ & ${ }_{n} q_{x}$ & ${ }_{n} p_{x}$ & $l_{x}$ & ${ }_{n} d_{x}$ & ${ }_{n} L_{x}$ & $T_{x}$ \\
\hline 60 & 5 & 2723040 & 23692 & 0.00870 & 0.5 & 0.04258 & 0.9574 & 91,889 & 3,912 & 449663 & $2,088,273$ & 22.73 \\
65 & 5 & 1934312 & 28893 & 0.01494 & 0.5 & 0.07200 & 0.9280 & 87,976 & 6,334 & 424047 & $1,638,610$ & 18.63 \\
70 & 5 & 1312330 & 36202 & 0.02759 & 0.5 & 0.12903 & 0.8710 & 81,642 & 10,534 & 381876 & $1,214,563$ & 14.88 \\
75 & 5 & 916477 & 43397 & 0.04735 & 0.5 & 0.21170 & 0.7883 & 71,108 & 15,053 & 317906 & 832,687 & 11.71 \\
80 & 5 & 481145 & 39372 & 0.08183 & 0.5 & 0.33966 & 0.6603 & 56,054 & 19,040 & 232673 & 514,781 & 9.18 \\
85 & 5 & 186894 & 24522 & 0.13121 & & 1.00000 & 0.0000 & 37,015 & 37,015 & 282108 & 282,108 & 7.62 \\
\hline
\end{tabular}


Table 4. Malaysian elderly life expectancy improvement by age group

\begin{tabular}{ccccccc}
\hline Age & \multicolumn{3}{c}{ Males } & \multicolumn{3}{c}{ Females } \\
& $1950-1955$ & $2010-2015$ & $\%$ of increment & $1950-1955$ & $2010-2015$ & $\%$ of increment \\
\hline 60 & 14.56 & 21.32 & $46 \%$ & 16.98 & 22.73 & $34 \%$ \\
65 & 11.41 & 17.77 & $56 \%$ & 13.62 & 18.63 & $37 \%$ \\
70 & 8.74 & 14.70 & $68 \%$ & 10.62 & 14.88 & $40 \%$ \\
75 & 6.69 & 12.27 & $83 \%$ & 8.25 & 11.71 & $42 \%$ \\
80 & 5.12 & 10.29 & $101 \%$ & 6.42 & 9.18 & $43 \%$ \\
85 & 4.07 & 9.07 & $123 \%$ & 5.20 & 7.62 & $46 \%$ \\
\hline
\end{tabular}

\section{CONCLUSION}

This paper estimates the life expectancy and its improvements among Malaysian elderlies in Malaysia using the life table approach. The analysis of central death rates showed that both males and females are increasing almost in linear pattern by age, associated with health problems that generally occurred at later ages. Comparison between genders shows that Elderly females have lower mortality rates than males at almost all ages, nonetheless, mortality improvement is higher for males. The estimation of mortality improvements clearly showed that recent elderly generations tend to live significantly higher than previous generation, hence informing policymakers to have a proper planning for social benefits related to elderlies. The results of this study can be useful for further research particularly that estimates the costs of pensions or long term care insurance.

\section{ACKNOWLEDGEMENTS}

We would like to express our deepest gratitude to the Ministry of Education (MOE) and Institute of Research Management \& Innovation, Universiti Teknologi MARA (UiTM) for the financial supports through Fundamental Research Grant Scheme with file number of 600-IRMI/FRGS 5/3 (125/2019) and for the permission to publish this journal.

\section{REFERENCES}

[1] A. C. Sanabria, "Population ageing: a global health crisis?," The Open University., 10.13140/RG.2.2.27212.36481. [Online]. Available: from https://www.open.edu/openlearn/health-sports-psychology/population-ageing-globalhealth-crisis/content-section-0, 2019.

[2] S. Eremina, "Population Ageing And China's Economy," The European Proceedings of Social \& Behavioural Sciences EpSBS., http://dx.doi.org/10.15405/epsbs.2018.04.16. [Online]. Available from http://earchive.tpu.ru/handle/11683/47254, 2018.

[3] E. Gurvich, "Pension Policy and Population Ageing," Journal of the New Economic Association, 42, issue 2, p. 177186, 2019.

[4] S. Kono, "Aging in Japan," Reviews in Clinical Gerontology. Cambridge University Press; 1996; 6(2):205-11.

[5] S. N. Shair, A. Y. Yusof, and N. H. Asmuni, "Evaluation of the product ratio coherent model in forecasting mortality rates and life expectancy at births by States," AIP Conference Proceedings 1842, 2017.

[6] L. T. Lee, "Preparing for ageing population," New Straits Times. [Online]. Available from https://www.nst.com.my/opinion/letters/2018/10/422166/preparing-ageing-population, 2018, October 17.

[7] N. A. Karim, H. Haron, N. Abdullah, and W. A. W. Adnan, "Intrinsic motivations for productive ageing," Indonesian Journal of Electrical Engineering and Computer Science, 13, 1228-1236, 10.11591/ijeecs.v13.i3.pp. 1228-1236, 2019.

[8] G. Coughlan, D. Epstein, A. Sinha and P. Honig, "q-Forwards: Derivatives for transferring longevity and mortality risk," JPMorgan Pension Advisory Group, Technical report, 2007.

[9] S. Ginette, "Life table Analysis. Mortality experience of the Aruban population," Central Bureau of Statistics, 2010.

[10] S. A. Ishak, S. N. Shair, W. N. A. W. A. Shukiman, and N. M. Radzi, "The Trends of Age and Gender Specific Mortality Rates by Ethnic Groups," Proceedings of the Third International Conference on Computing, Mathematics and Statistics (iCMS2017), Springer, Singapore, 2019.

[11] A. Omar, S. S. Ganapathy, M. A. M. Fuad, and Y. Y. Khoo, "Cause-specific mortality estimates for Malaysia in 2013: results from a national sample verification study using medical record review and verbal autopsy," BMC public health, 19(1), 110. doi:10.1186/s12889-018-6384-7, 2019.

[12] M. A. Bujang, A. M. A. Hamid, N. A. Zolkepali, N. M. Hamedon, S. S. M. Lazim, and J. Haniff, "Mortality rates by specific age group and gender in Malaysia: Trend of 16 years, 1995 - 2010," Journal of Health Informatics in Developing Countries., Vol. 6, pp. 521-529, 2012.

[13] United Nations, "Department of Economic and Social Affairs, Population Division (2019)," World Population Prospects 2019, Online Edition.

[14] H. P. Kohler and I. V. Kohler, "Frailty modelling for adult and old age mortality: The application of a modified DeMoivre hazard function to sex differentials in mortality," Demographic Research, 3(8), 32, http://dx.doi.org/10.4054/DemRes.2000.3.8, 2000. 
[15] D. Gu, P. Gerland, K. F. Andreev, N. Li, T. Spoorenberg, and G. Heilig, "Old-age mortality in Eastern and SouthEastern Asia," Demographic Research, 29: 999-1038, http://dx.doi.org/10.4054/DemRes.2013.29.38, 2013.

[16] C. M. Igwenagu, "The Application of Life Table Functions: A Demographic Study," IOSR Journal of Mathematics., Volume 10, 80-82, 10.9790/5728-10148082, pp80-82, 2014.

[17] M. J. Reding and E. Potes, "Rehabilitation outcome following initial unilateral hemispheric stroke. Life table analysis approach," Stroke; 19:1354, 1988.

[18] A. D. Lopez, J. Salomon, O. Ahmad, C. J. Murray, and D. Mafat, "Life tables for 191 countries: data, methods and results," Geneva: World Health Organization. Available from http://www.who.int/iris/handle/10665/67772, 2001.

[19] M. H. Omar, N. H. Asmuni, and S. N. Shima, "Healthy life expectancy vs health expenditure by sullivan method in Malaysia," Indonesian Journal of Electrical Engineering and Computer Science, 14, 402-406. 10.11591/ijeecs.v14.i1.pp402-406, 2019.

[20] P. Antolin, "Longevity Risk and Private Pensions," OECD Working Papers on Insurance and Private Pensions, No. 3, OECD Pubishing. Doi: 10.1787/2160613084, 2007.

[21] T. A. T. A. Hamid, "Population Ageing in Malaysia: A mosaic of Issues, challenges and prospects," Serdang, Malaysia: Penerbit Universiti Putra Malaysia Press, 2015.

[22] N. A. Malik, Z. Wahid, A. F. Zulkipili, and S. N. Ibrahim, "Investigation of lower limb's muscles activity during performance of salat between two age groups," Indonesian Journal of Electrical Engineering and Computer Science, 14, 608-617, 10.11591/ijeecs.v14.i2.pp608-617, 2019.

[23] E. M. Crimmins, H. Shim, Y. S. Zhang, and J. K. Kim, "Differences between men and women in mortality and the health dimensions of the morbidity process," Clinical Chemistry, 65 (1) , pp. 135-145, 2019.

[24] V. Zarulli, J. A. B. Jones, A. Oksuzyan, R. Lindahl-Jacobsen, K. Christensen, and J. W. Vaupel, "Women live longer than men even during severe famines and epidemics," Proceedings of the National Academy of Sciences USA 115:E832-E840, 2018.

[25] H. Beltrán-Sánchez, C. E. Finch, and E. M. Crimmins, "Twentieth century surge of excess adult male mortality," Proceedings of the National Academy of Sciences USA 112:8993-8998, 2015.

[26] E. Arias, "United States Life Tables, 2000," National Vital Statistics Reports, 51:3. Hyattsville, MD: National Center for Health Statistics, 2002.

\section{BIOGRAPHIES OF AUTHORS}

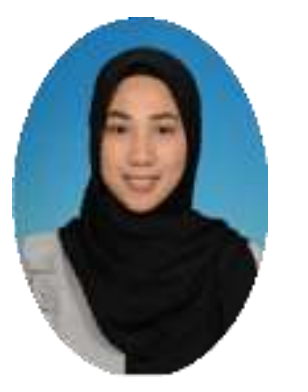

Nur Shatikah Binti Mohamad Ibrahim obtained Bachelor of Science (Hons) Actuarial Science from Universiti Teknologi MARA (UiTM), Malaysia in 2019. She is currently a Master student at the Faculty of Computer and Mathematical Sciences, UiTM Shah Alam.

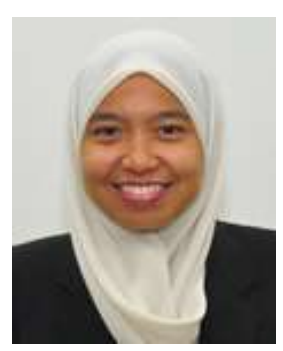

Syazreen Niza Binti Shair is a Senior Lecturer from the Centre of Actuarial Studies, Faculty of Computer and Mathematical Sciences, Universiti Teknologi MARA Shah Alam. She obtained her $\mathrm{PhD}$ in Applied Finance and Actuarial Studies from the Macquarie University, Sydney, Australia. Her main area of research include population studies, mortality forecasting, fertility forecasting, longevity risk and long term care.

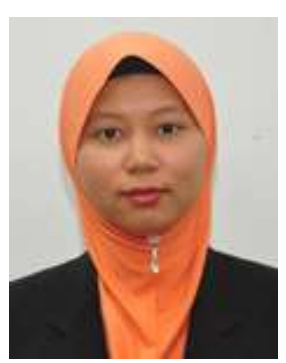

Aida Yuzi Yusof is a Senior Lecturer from the Centre of Actuarial Studies, Faculty of Computer and Mathematical Sciences, Universiti Teknologi MARA Shah Alam. Her research areas include Actuarial mathematics, financial economics and Islamic Finance. 